\title{
Seed dormancy varies widely among Arabidopsis thaliana populations both between and within Fennoscandia and Italy
}

\author{
Giulia Zacchello ${ }^{1}$, Svenja Bomers ${ }^{2}$, Cecilia Böhme ${ }^{2}$, Froukje Postma ${ }^{2}$, and Jon Agren ${ }^{2}$ \\ ${ }^{1}$ Uppsala Universitet \\ ${ }^{2}$ Uppsala University
}

April 12, 2021

\begin{abstract}
The timing of germination is a key life-history trait in plants, which is strongly affected by the strength of seed dormancy. Continental-wide variation in seed dormancy has been related to differences in climate and the timing of conditions suitable for seedling establishment. However, for predictions of adaptive potential and consequences of climatic change, information is needed regarding the extent to which seed dormancy varies within climatic regions and the factors driving such variation We planted 17 Italian and 28 Fennoscandian populations of Arabidopsis thaliana in the greenhouse and at two field sites in Italy and Sweden. To identify possible drivers of among-population variation in seed dormancy, we examined the relationship between seed dormancy and climate at the sites where populations were originally sampled. Seed dormancy was on average stronger in the Italian compared to the Fennoscandian populations, but also varied widely within both regions. Estimates of seed dormancy in the three maternal environments were positively correlated, but seeds had on average stronger dormancy when produced in the greenhouse than at the two field sites. Among Fennoscandian populations, seed dormancy tended to increase with increasing summer temperature and decreasing precipitation at the site of origin. In the smaller sample of Italian populations, no significant association was detected between mean seed dormancy and climate at the site of origin. The correlation between seed dormancy and climatic factors in Fennoscandia suggests that at least some of the among-population variation is adaptive and that climate change will affect selection on this trait.
\end{abstract}

\section{Seed dormancy varies widely among Arabidopsis thalianapopulations both between and within} Fennoscandia and Italy

\section{Authors}

Giulia Zacchello, Plant Ecology and Evolution, Department of Ecology and Genetics, EBC, Uppsala University, Norbyvägen 18 D, SE-752 36 Uppsala, Sweden; giulia.zacchello@ebc.uu.se; ORCID ID 0000-0002-25787685 (corresponding author)

Svenja Bomers, Plant Ecology and Evolution, Department of Ecology and Genetics, EBC, Uppsala University, Norbyvägen 18 D, SE-752 36 Uppsala, Sweden; Current address: Institute for Seed and Propagating Material, Phytosanitary Service and Apiculture, Austrian Agency for Health and Food Safety, Spargelfeldstraße 191, 1220 Vienna, Austria; svenja.bomers@ages.at

Cecilia Böhme, Plant Ecology and Evolution, Department of Ecology and Genetics, EBC, Uppsala University, Norbyvägen 18 D, SE-752 36 Uppsala, Sweden; cecilia.bohme@hotmail.com

Froukje Postma, Plant Ecology and Evolution, Department of Ecology and Genetics, EBC, Uppsala University, Norbyvägen 18 D, SE-752 36 Uppsala, Sweden; froukjemarije@gmail.com

Jon Ågren, Plant Ecology and Evolution, Department of Ecology and Genetics, EBC, Uppsala University, Norbyvägen 18 D, SE-752 36 Uppsala, Sweden; jon.agren@ebc.uu.se; ORCID ID 0000-0001-9573-2463 


\begin{abstract}
The timing of germination is a key life-history trait in plants, which is strongly affected by the strength of seed dormancy. Continental-wide variation in seed dormancy has been related to differences in climate and the timing of conditions suitable for seedling establishment. However, for predictions of adaptive potential and consequences of climatic change, information is needed regarding the extent to which seed dormancy varies within climatic regions and the factors driving such variation
\end{abstract}

We planted 17 Italian and 28 Fennoscandian populations of Arabidopsis thaliana in the greenhouse and at two field sites in Italy and Sweden. To identify possible drivers of among-population variation in seed dormancy, we examined the relationship between seed dormancy and climate at the sites where populations were originally sampled.

Seed dormancy was on average stronger in the Italian compared to the Fennoscandian populations, but also varied widely within both regions. Estimates of seed dormancy in the three maternal environments were positively correlated, but seeds had on average stronger dormancy when produced in the greenhouse than at the two field sites. Among Fennoscandian populations, seed dormancy tended to increase with increasing summer temperature and decreasing precipitation at the site of origin. In the smaller sample of Italian populations, no significant association was detected between mean seed dormancy and climate at the site of origin.

The correlation between seed dormancy and climatic factors in Fennoscandia suggests that at least some of the among-population variation is adaptive and that climate change will affect selection on this trait.

\title{
Keywords
}

climate change; germination proportion; maternal environment effect; regional variation; timing of germination.

\section{Introduction}

The timing of seed germination affects fitness by determining conditions during seedling establishment and growth (Donohue et al. 2010; Postma and Ågren 2016), but may also influence fitness by having cascading effects on later life-history traits such as flowering start (Evans and Cabin 1995; Donohue 2002; Wilczek et al. 2009; Akiyama and Ågren 2014; Burghardt et al. 2015; Martínez-Berdeja et al. 2020; Zacchello et al. 2020). In seasonal environments, there should be strong selection for timing of germination matching periods favourable for seedling establishment and growth (Donohueet al. 2010; Wadgymar et al. 2015), and adjustment of germination timing is expected to critically affect the ability of species to adapt to climate change (Fenner and Thompson 2005; Cochraneet al. 2015). The degree to which among-population variation in seed dormancy is related to climatic differences across different spatial scales thus becomes of considerable interest for assessing the potential of adaptive evolution in response to climate change (Dawsonet al. 2011).

In many species, timing of germination is regulated by the strength of seed dormancy. Primary seed dormancy, i.e., dormancy at the time of seed maturation, and the rate at which it is lost will determine when seed germination will be triggered in response to environmental cues (Vleeshouwers et al. 1995; Li and Foley 1997; Finch-Savage and Leubner-Metzger 2006; Bewley et al. 2013; Baskin and Baskin 2014). Optimal seed dormancy should be positively correlated with the length of the period following seed release that is unfavourable for seedling establishment (Meyer and Monsen 1991; Allen and Meyer 1998; Llorens et al. 2008; Wagmann et al. 2012), and may thus vary among populations. Genetic variation in seed dormancy has been documented among populations of several species and across various spatial scales, for example in Arabidopsis thaliana within Europe (Kronholm et al. 2012; Debieu et al. 2013), inBromus tectorum in North America (Allen and Meyer 2002), and inDigitaria melanjiana in central and eastern Africa (Hacker 1984). Several environmental factors may drive divergence of seed dormancy, and one approach to identify potential agents of selection is to examine the correlation between phenotype and environment at the site of origin (Wadgymar et al. 2017). Characterizing spatial variation in seed dormancy and its association with differences in environmental factors can thus provide an insight to the possible drivers of such variation. 
Among-population variation in seed dormancy can be the result not only of genetic differentiation, but also of environmental effects and the interaction between these two factors (Young et al. 1991; Benderet al. 2003; Schütz and Rave 2003; Donohue et al. 2005; Donohue 2009; Postma and Ågren 2015; Fenner 2018). Most studies that document within-species variation in seed dormancy have grown populations in the greenhouse (e.g., Allen \& Meyer, 2002; Debieu et al., 2013; Kronholm et al., 2012; Vidigal et al., 2016; Wagmann et al., 2012). However, plants raised in the greenhouse are typically exposed to temperature, light and watering regimes that are very different from those experienced in natural populations. Studies comparing dormancy of seeds produced in the greenhouse and in the field have also detected strong genotype $\times$ maternal environment interactions (Schütz and Rave 2003; Fernández-Pascual et al. 2013; Postma and Ågren 2015). To determine the importance of genetic differentiation, environmental effects and their interaction for variation in seed dormancy, seeds of different source populations should thus ideally be produced in multiple relevant field environments (Young et al. 1991; Schütz and Milberg 1997).

In this study, we quantify variation in primary seed dormancy among populations of the annual model organism A. thaliana in two regions in Europe and examine the association between within-region variation in seed dormancy and climate. A. thaliana is native to Africa and Eurasia (Durvasula et al. 2017), and occurs in habitats that vary widely in the length of the dry summer period. In winter-annual populations of $A$. thaliana, seeds are matured in late spring and early summer and germinate in autumn (Âgren and Schemske 2012). As in other species with physiological dormancy, germination in A. thaliana cannot occur until seed dormancy has been released by a process called after-ripening (Finch-Savage and Leubner-Metzger 2006; Montesinos-Navarro et al. 2012). Considerable within-species variation in the required length of afterripening has been observed at different spatial scales, but its association with climatic factors is still unclear. Kronholm et al. (2012) found a negative association between seed dormancy and summer precipitation among European populations, and Vidigal et al. (2016) similarly found that high dormancy was associated with high temperature and low summer precipitation within the Iberic peninsula. By contrast, Debieu et al. (2013) found no climatic association but only a latitudinal cline across Europe. Moreover, in a study of regional variation in north-eastern Spain, high primary dormancy was associated with dry, but cold environments of origin (Montesinos-Navarro et al. 2012), indicating that large-scale climatic associations are not necessarily reflected at smaller spatial scales. Additional studies of regional variation are therefore needed to characterize spatial patterns of seed dormancy differentiation in A. thaliana . Furthermore, seed dormancy in $A$. thaliana is strongly affected by the maternal environment and by the interaction between genotype and maternal environment (Postma \& Ågren, 2015), suggesting that the possibility of such interactions should be considered when examining correlations between trait expression and environment at site of origin.

Here, we planted individuals from 28 Fennoscandian populations and 17 Italian populations (4-5 maternal lines per population for a total of 224 maternal lines) in three common gardens, one at the site of a natural population in north-central Sweden, one at the site of a natural population in central Italy, and one in a greenhouse in Uppsala, Sweden (Fig. 1 ). Fennoscandia and Italy represent the northern and southern range margins of $A$. thaliana in Europe. The summer period during which intermittent droughts is likely to kill any young emerging seedlings is longer in Italy compared to Fennoscandia (Fig. 2A and B ). Consequently, we expect Italian populations to show stronger seed dormancy than Fennoscandian populations, as previously observed in a comparison between the populations native to the Swedish and Italian field sites used in the present study (Postma and Ågren 2015). Similarly, within regions, seed dormancy can be expected to be positively correlated with the length of the period with summer conditions and with temperature during this period, and negatively correlated with precipitation during summer.

We tested the hypotheses that (i) dormancy of seeds produced by Italian populations is stronger than that of seeds produced by Fennoscandian populations, (ii) seed dormancy is affected by the maternal environment and its interaction with region and population of origin, and (iii) within regions, seed dormancy is related to climatic conditions at the site of origin in summer.

\section{Materials and Methods}

Seed collection 
For the present study, seeds of natural populations of Arabidopsis thaliana (L.) Heynh. were collected at 45 sites in Fennoscandia and Italy (Fig. 1, Table S1 ) between 2005 and 2012. We sampled 28 populations in Fennoscandia (latitude, $55^{\circ} 58^{\prime} \mathrm{N}-66^{\circ} 88^{\prime} \mathrm{N}$; longitude $6^{\circ} 62^{\prime} \mathrm{E}-24^{\circ} 38^{\prime} \mathrm{E}$ ) and 17 in Italy (latitude, $37^{\circ} 80^{\prime}$ $-42^{\circ} 39^{\prime}$; longitude $\left.12^{\circ} 00^{\prime}-18^{\circ} 34^{\prime} \mathrm{E}\right)$. Seeds were kept in paper bags at room temperature until use. Prior to the present experiment, seed collections had gone through two generations of selfing in the greenhouse to reduce maternal environmental effects.

\section{Seed production}

To document the effects of population of origin and seed maturation environment on seed dormancy, we grew plants in three different environments: the greenhouse and at the field sites from which two of the sampled populations originated, one located in central Italy (Castelnuovo di Porto $42^{\circ} 07^{\prime} \mathrm{N}, 12^{\circ} 29^{\prime} \mathrm{E}$ ) and one in north-central Sweden (Rödåsen $62^{\circ} 48^{\prime} \mathrm{N}, 18^{\circ} 12^{\prime} \mathrm{E}$ ). To produce plants for the three environments, seeds of five maternal lines from each population (a total of 225 lines) were sown on agar (on 18-21 August 2015 for plants to be grown in the greenhouse and at the Swedish site, and on 15-16 October 2015 for plants to be grown at the Italian site), stratified for 7 days at $4^{\circ} \mathrm{C}$ in darkness and then moved to a growth room for 8 days $\left(22{ }^{\circ} \mathrm{C} 16 \mathrm{~h}\right.$ light with photosynthetically active radiation [PAR] of $150 \mu \mathrm{mol} \mathrm{m} \mathrm{m}^{-2} \mathrm{~s}^{-1}$ and $16{ }^{\circ} \mathrm{C} 8$ $\mathrm{h}$ dark). Only one line did not succeed in producing seedlings for the transplant. The following five days, emerging seedlings to be grown in the greenhouse were transplanted to $5 \times 5 \mathrm{~cm}$ pots filled with commercial potting soil (two pots per line; one seedling per pot), whereas plants to be grown at the field sites were transferred to randomized positions in plug trays (299 plugs per tray, plug size $2 \times 2 \times 4 \mathrm{~cm}$ ) filled with local soil in Italy and with a mixture of sand, soil and unfertilized peat in Sweden. The three outer rows in each tray (39 positions) were considered edge positions. At each field site, 24 replicates per line were planted in non-edge positions, for a total of 10,800 plants at the two sites.

In the greenhouse, plants were grown in a randomized design at $20{ }^{\circ} \mathrm{C} 16 \mathrm{~h}$ light and $16{ }^{\circ} \mathrm{C} 8 \mathrm{~h}$ dark, and were divided into four cohorts based on their timing of bolting and seed maturation. After 3 weeks, 23 lines (3 Fennoscandian and 20 Italian) had bolted. These plants (cohort 1) were kept in the greenhouse, whereas the remaining plants were moved to a growth room for vernalization. The latter plants were in the growth room exposed to $12{ }^{\circ} \mathrm{C} 8 \mathrm{~h}$ light with PAR of $150 \mu \mathrm{mol} \mathrm{m} \mathrm{s}^{-1}$ and $12{ }^{\circ} \mathrm{C} 16 \mathrm{~h}$ dark for one week, $6{ }^{\circ} \mathrm{C} 8 \mathrm{~h}$ light with PAR of $50 \mu \mathrm{mol} \mathrm{m} \mathrm{m}^{-2} \mathrm{~s}^{-1}$ and $6{ }^{\circ} \mathrm{C} 16 \mathrm{~h}$ dark for six weeks, and then back to $12{ }^{\circ} \mathrm{C} 8 \mathrm{~h}$ light at $150 \mu \mathrm{mol} \mathrm{m} \mathrm{m}^{-2} \mathrm{~s}^{-1}$ and $12{ }^{\circ} \mathrm{C} 16 \mathrm{~h}$ dark for one week, after which they were returned to the greenhouse. Seeds produced by plants in the first cohort were harvested when the plants had spent a total of 8 weeks in the greenhouse. Seeds produced by the following cohorts were harvested 7 weeks (cohort 2), 8 weeks (cohort 3), and 11 weeks (cohort 4) after return to the greenhouse. At harvest, seeds from the 20 most recently matured fruits of each plant were collected. All collected seeds were stored in paper envelopes under dry conditions in the growth room used for the germination assays $\left(20{ }^{\circ} \mathrm{C} 16 \mathrm{~h}\right.$ and $\left.16{ }^{\circ} \mathrm{C} 8 \mathrm{~h}\right)$ until germinability was tested.

Plants to be grown in the field were transported to the field sites within six days after the transfer to trays. At the field sites, trays with plants were sunk into the ground (Italy, 7 November 2015; Sweden, 11 September 2015; following procedures outlined in Ågren \& Schemske, 2012; Postma \& Ågren, 2016), and exposed to natural field conditions until harvest of seeds (Italy, 22-24 April 2016; Sweden, 1-3 July 2016). At the time of transfer to the field, seedlings had produced one-two pairs of true leaves, and were at the same stage of development as naturally establishing seedlings at the experimental sites. At harvest, seeds were collected from plants in non-edge positions.

\section{Germination and viability assays}

Germination rate under standardized conditions was used to quantify seed dormancy (as in Postma and Ågren 2015). Only lines that had produced at least 150 seeds were included in germination tests. For seeds produced in the greenhouse, we monitored changes in seed dormancy over time by determining the proportion of viable seeds germinating 1, 3, 12, 30 and 54 weeks after harvest. Due to limited seed availability, dormancy of seeds produced at the two field sites was possible to test only once. For these seeds, we chose to test germinability 12 weeks after harvest, because this was the time point at which variation among recombinant inbred lines 
derived from a cross between an Italian and a Swedish A. thaliana population was highest in a previous study of dormancy of seeds produced at the two field sites (Postma and Ågren 2015). In all tests, about 30-100 seeds of each line were sown on 2 filter papers watered with $2 \mathrm{~mL}$ of demineralized water in each of three petri dishes. After sowing, petri dishes were placed in a growth room and regularly watered for one week $\left(20{ }^{\circ} \mathrm{C} 16 \mathrm{~h}\right.$ light with photosynthetically active radiation of $150 \mu \mathrm{mol} \mathrm{m}{ }^{-2} \mathrm{~s}^{-1}$ and $16{ }^{\circ} \mathrm{C} 8 \mathrm{~h}$ dark). One week after sowing, we recorded for each line the number of germinated seeds and the total number of seeds sown.

To quantify germination proportion as number seeds germinating per viable seed sown, we tested seed viability of lines with a germination proportion below $95 \%$ in a given maternal environment by exposing seeds to conditions expected to break any seed dormancy. About 50 seeds per line were sown on agar in petri dishes under sterile conditions. The petri dishes with sown seeds were kept in darkness at $6{ }^{\circ} \mathrm{C}$ for two weeks, and then moved to randomized positions in a growth room $\left(22^{\circ} \mathrm{C} 16 \mathrm{~h}\right.$ light with photosynthetically active radiation of $150 \mu \mathrm{mol} \mathrm{m} \mathrm{m}^{-2} \mathrm{~s}^{-1}$ and $16{ }^{\circ} \mathrm{C} 8 \mathrm{~h}$ dark). Viability was scored as proportion of seeds that had germinated after two weeks in the growth room (see Postma \& Ågren, 2015). If the viability of a given line was below $95 \%$, its viability was tested a second time and the mean viability of the two tests was used in the analysis. We estimated number of seeds germinating per viable seed using the expression, number germinated seeds/(number of seeds sown $\times$ proportion viable seeds), and included only lines that had a mean viability greater than $95 \%$ in the statistical analysis of variation in seed dormancy. In total, we included in the analysis 214 lines representing 45 populations grown in the greenhouse, 172 lines representing 43 populations grown at the Italian site, and 108 lines representing 28 populations grown at the Swedish site.

\section{Climatic data}

To characterize summer conditions at sites of origin, we selected the following five bioclimatic variables from the WorldClim database (Fick and Hijmans 2017): annual mean temperature, maximum temperature of warmest month, mean temperature of warmest quarter, annual precipitation, precipitation of warmest quarter (see Fig. 2A and B, and Table S2 for regional ranges). For all sites, the warmest quarter of the year occurs between June and September (Fig. 2A and B ).

\section{Statistical analysis}

We used mixed-effect ANOVA to examine the effects of region of origin (Italy vs. Fennoscandia), maternal environment (greenhouse vs. Italy field site) and their interaction (fixed effects), and population nested within region of origin and its interaction with maternal environment (random effects) on germination proportion 12 weeks after seed maturation. The analysis was based on line means. We included in the analysis only populations with germination proportions available for both the greenhouse and the Italian maternal environments (43 populations in total). Seeds from the Swedish field site could not be included due to low seed production of Italian populations. The response variable was arcsine square-root transformed prior to analysis to obtain a normal distribution of residuals. Because of heteroscedasticity, variance was allowed to vary among regions of origin. Statistical significance of fixed explanatory variables was determined by F-tests with type III Sums of Squares and Kenward-Rogers adjustment for degrees of freedom, while significance of random factors was tested using Likelihood Ratio Tests between full and reduced models. The analysis was performed using the $\mathrm{R}$ package 'nlme'.

Additionally, we tested the effect of maternal environment, population and their interaction on germination proportions of Fennoscandian populations collected at the two field sites. We included in the analysis only populations with germination proportions available for both field maternal environments (18 populations in total). The response variable was arcsine square-root transformed and statistical significance of the effect variables was determined by F-tests with type III Sums of Squares.

To assess the association between climate at the site of origin and germination proportion up to 12 weeks after seed maturation, we first conducted a scaled and centered principal component analysis (PCA) among the five climatic variables for each of the two regions separately using the R function prcomp from the 'base' package. The first three Principal Components (PCs) cumulatively explained $99 \%$ of the total variation in both regions (Table S3 ). We then used these PCs as independent variables in multiple regressions with 
mean germination proportion of populations (based on line means) as response variable. We chose to use principal components rather than the original climatic variables as predictors in the multiple regression to avoid the problem of collinearity among the chosen climatic variables. In addition, to assess spatial variation in seed dormancy within regions, we tested the relationship between population mean germination proportions, and latitude, longitude and their interaction using linear models analyzed separately by region. These analyses were restricted to estimates of seed germinability up to 12 weeks after seed maturation. Estimates of dormancy obtained soon after seed maturation are arguably the estimates most directly related to dormancy of seeds in natural environments due to post-dispersal environmental effects and their interaction with the maternal environment on seed dormancy release (Postma et al.2016; Coughlan et al. 2017; Buijs et al. 2020). Hence, the correlation between environmental conditions at the site of origin and estimates of seed dormancy is likely to decrease with time after seed maturation in our experiments.

Seeds produced in the greenhouse by plants in cohort 1 had markedly higher germination proportions than seeds produced by the other cohorts, most likely due to absence of the vernalization treatment. However, removal of cohort 1 from the dataset did not affect the statistical significance nor markedly change effect sizes, and the analyses presented below include cohort 1 .

All statistical analyses were conducted in $\mathrm{R}$ version 3.4.0 (R Core Team, 2017).

\section{Results}

\section{The effect of region of origin and maternal environment on dormancy level}

Seeds produced by Italian populations had on average stronger seed dormancy 12 weeks after seed maturation than had seeds produced by Fennoscandian populations both at the Italian field site and in the greenhouse $\left(\mathrm{F}_{1,41}=69.7, \mathrm{p}<0.001\right.$, Fig. 3A and Table 1$)$. At the Swedish field site, very few Italian populations managed to produce sufficient amounts of seeds to allow germination tests. However, the few lines tested tended to produce seeds with stronger dormancy compared to the seeds produced by Fennoscandian populations also at that site (Fig. 3A andTable $\mathbf{1}$ ).

Germination proportions were on average $37 \%$ higher among seeds matured at the Italian field site compared to those matured in the greenhouse $\left(\mathrm{F}_{1,331}=15.4, \mathrm{p}<0.001\right)$, and this effect did not vary with region of origin (region of origin $\times$ maternal environment interaction, $\mathrm{F}_{1,331}=1.2, \mathrm{p}=0.27$; Fig. 3A and Table $\mathbf{1}$ ). Germination proportions varied among populations within regions (L-ratio $6,7=107.5, \mathrm{p}<0.001$, Fig. 3A and Table 1 ). Although germination proportions $12 \mathrm{wk}$ after seed maturation in each of the three maternal environments were positively correlated (Spearman rank correlation, Italy field vs. Sweden field, $\mathrm{r}_{\mathrm{s}}=0.63, \mathrm{~N}$ $=30, \mathrm{p}<0.001$; Italy field vs. Greenhouse, $\mathrm{r}_{\mathrm{s}}=0.52, \mathrm{~N}=43, \mathrm{p}<0.001$; Sweden field vs. Greenhouse, $\mathrm{r}_{\mathrm{s}}=$ $0.88, \mathrm{~N}=32, \mathrm{p}<0.001$ ), the effect of population differed between the two maternal environments (significant population $\times$ maternal environment interaction, $\mathrm{L}_{-\mathrm{ratio}_{7,9}}=158.8, \mathrm{p}<0.001$, Fig. 3A and Table 1 ). The interaction reflected the fact that variance in germination proportion among Fennoscandian populations 12 weeks after seed maturation was much larger when seeds had been produced in the greenhouse compared to when matured at the Italian site, whereas for Italian populations the opposite was true (Fig. 3A ). For both regions of origin, the highest variance in population means was observed when the overall mean germination proportion was intermediate (seeds of Fennoscandian populations grown in the greenhouse, and of Italian populations grown at the Italian field site) rather than very high (Fennoscandian populations at the Italian field site) or very low (seeds of Italian populations in the greenhouse; Fig. 3A ). The seeds of all populations except one (Ørnes, the northernmost sampled population from Fennoscandia) had higher germination proportions when matured in Italy compared to in the greenhouse. Removal of this population from the dataset did not affect the significance of the population $\times$ maternal environment interaction (not shown).

Germination proportions of seeds produced at the two field sites varied among Fennoscandian populations $\left(\mathrm{F}_{17,113}=11.3, \mathrm{p}<0.001\right.$, Fig. 3Aand Table 2$)$, and the variance among populations was markedly larger for seeds produced at the Swedish field site compared to seeds produced at the Italian field site (maternal environment x population interaction, $\mathrm{F}_{17,113}=5.4, \mathrm{p}<0.001$, Fig. 3A and Table 2 ). 
Among seeds matured in the greenhouse, Fennoscandian populations had on average higher germination proportions than had Italian populations in all tests conducted during one year of after-ripening. The average germination proportion of Fennoscandian populations increased from about $10 \%$ one week after seed harvest to $50 \%$ eleven weeks later, and reached a maximum of about $75 \%$ after one year of after-ripening (Fig. 3B ). By contrast, the average germination proportion of Italian populations was below $17 \%$ during the first 12 weeks of after-ripening, and reached $50 \%$ only after one year (Fig. 3B ). Still after 54 weeks of after-ripening, germination proportion varied widely among both Fennoscandian and Italian populations (Fig. 3B ).

\section{Seed dormancy vs. climate at site of origin}

Factor loadings of climatic variables on PCs are shown in Table $\mathbf{3}$ and Figure S4 . Within Fennoscandia, mean temperature of the warmest month and of the warmest quarter decreased with PC1, while mean annual precipitation and mean precipitation during the warmest quarter increased with PC1. Annual temperature was instead negatively associated with PC2. For seeds produced by Fennoscandian populations in the greenhouse, germination proportions quantified 1 and 3 weeks after seed maturation tended to increase with PC1 (germination proportion 1 week: partial linear regression coefficient, $\beta=0.0387, \mathrm{P}=0.033$; germination proportion 3 weeks: $\beta=0.0799, \mathrm{P}=0.003$, Table 4 ), whereas no association was found with $\mathrm{PC} 2$ or PC3. Seed dormancy thus tended to be stronger in populations from sites with relatively high summer temperature and low precipitation than in populations originating from sites with low summer temperature and high precipitation.

Within Italy, temperature variables increased with $\mathrm{PC} 1$, and precipitation variables increased with $\mathrm{PC} 2$ (Table 3 ). Mean annual precipitation was positively associated with PC3, while mean precipitation during the warmest quarter showed an opposite trend (Table 3 ). Germination proportions of seeds produced by Italian populations in the greenhouse were very low 1 and 3 weeks after seed maturation (Fig. 3A ) and were not significantly associated with any PC.

No significant association was found between PCs and germination proportions of seeds 12 weeks after harvest in the greenhouse or in the field (Table 4 ), and mean germination proportions did not vary with latitude or longitude of origin in either region $(\mathrm{P}>0.05$, not shown).

\section{Discussion}

This study has shown that across three different seed production environments, Fennoscandian and Italian Arabidopsis thalianapopulations differ consistently in seed dormancy. As expected from differences in summer temperature and precipitation, Italian populations produced seeds with stronger dormancy than did Fennoscandian populations. In addition, we found wide variation in dormancy among populations within each of the two geographic regions, and that for most populations seed maturation environment had a strong effect on seed dormancy. Below we discuss the results in relation to previous studies documenting variation in seed dormancy among and within geographic regions, effects of seed maturation environment on dormancy level, and processes affecting population differentiation in this trait.

The stronger dormancy of seeds produced by Italian compared to Fennoscandian populations is in accordance with expectations based on climatic differences between the two regions. In the Italian populations sampled, seed maturation in late April is followed by a long, hot and dry summer, during which germination in response to occasional rain is bound to be associated with high seedling mortality. By comparison, the length of the period after seed maturation that is unfavourable for seedling establishment is markedly shorter in Fennoscandian populations. As a result, selection is expected to favour stronger primary seed dormancy in the Italian compared to the Fennoscandian populations (cf. Postma \& Ågren, 2016). In experiments conducted at the two field sites, August was identified as the optimal time of germination at the Swedish site (Akiyama and Ågren 2014), and November at the Italian site (Zacchello et al. 2020). The difference in seed dormancy between Italian and Fennoscandian populations documented in the present study is consistent with previous observations indicating a decrease in seed dormancy with increasing latitude of origin among A. thalianaaccessions sampled across Europe (Kronholm et al. 2012; Debieuet al. 2013), and is likely to be representative for differences between north European populations and southern populations at low altitude 
in general.

Seed dormancy was strongly affected not only by the region of origin but also by the maternal environment. Seed dormancy after 12 weeks of after-ripening was stronger among seeds produced at the Swedish field site than among seeds produced at the Italian field site, which is consistent with differences observed in a former study documenting seed dormancy of a population of recombinant inbred lines (RILs) planted at the two sites and in the greenhouse (Postma and Ågren, 2015). Differences in temperature during seed maturation may have contributed to the observed difference in seed dormancy between the two field sites. Low temperature during seed maturation has been found to increase seed dormancy of $A$. thaliana (Chiang et al. 2011; Footittet al. 2011, 2013; Kendall and Penfield 2012; He et al.2014; Coughlan et al. 2017; Kerdaffrec and Nordborg 2017), but also in a wide range of other species including Avena fatua, Beta vulgaris, Chenopodium bonus-henricus, andPlantago lanceolata (see review Fenner 2018). During the two months preceding seed dispersal (i.e., March and April in Italy, and May and June in Sweden), air temperature was 1.5 @C colder in Sweden than in Italy (Italy: $12.7 @ \mathrm{C}$; Sweden: $11.2 @ \mathrm{C}$; data recorded at the sites using loggers as in Ågren \& Schemske, 2012).

More surprising was the low germinability of seeds 12 weeks after harvest in the greenhouse (Fig. 3 ). Because temperature in the greenhouse was higher than at the field sites during seed maturation, we expected seeds produced in the greenhouse to have the lowest dormancy, as observed in the experiment with the RIL population (Postma and Ågren 2015). The present results indicate that environmental effects on development of seed dormancy may vary among experiments also in a greenhouse with a rather well-controlled temperature regime. Further studies are needed to examine the possible influence of differences in soil nutrient concentrations (Baskin and Baskin 2014) and water content (Alboresi et al. 2005) for seed dormancy development in this environment.

Correlations between germination proportions and measures of climate at sites of origin were generally weak, and statistically significant only for seeds produced by Fennoscandian populations in the greenhouse (Table 2 ). One and three weeks after maturation, seed dormancy tended to be negatively related to precipitation and positively related to summer temperature at the sites of origin (Table 3 ). These correlations are in line with predictions, and with associations between seed dormancy and climate observed within the Iberic peninsula (Vidigalet al. 2016), and at a larger scale across Europe (Kronholmet al. 2012). In contrast to correlations documented for the Fennoscandian populations, primary seed dormancy increased from sites characterized by high temperature and wet conditions to those characterized by lower temperature and dryer conditions among $A$. thaliana populations sampled along an altitudinal gradient in north-eastern Spain (MontesinosNavarro et al., 2012). The contrasting results show that correlations between seed dormancy and climatic variables vary among regions, and suggest that the strength and direction of correlations with different climatic variables will depend on which part of the overall climatic variation is examined.

There are several possible reasons for the generally weak correlations between primary seed dormancy and large-scale climatic variation within regions, and the lack of statistically significant associations for Italian populations. First, more populations were sampled in Fennoscandia and the climatic range represented by these populations was wider than that represented by the Italian populations (Table S2 ), which should increase the chance of detecting relationships between seed dormancy and environmental variables. Second, lower survival and fecundity in the field compared to the greenhouse resulted in smaller sample sizes, which should have reduced precision of estimates and statistical power in analyses of variation in dormancy among seeds matured in the field. Third, large-scale climatic data may not well represent local microclimate since the latter is strongly influenced by topography and exposure. For example, most of the northernmost populations grow on steep, south-facing slopes, which represent particularly warm and dry habitats in the landscape. Fourth, in addition to micro-climatic conditions, optimal germination time and seed dormancy may depend on environmental factors, such as soil composition, which affects water-holding capacity, and on vegetation cover, which affects intensity of competitive interactions. Fifth, seed dormancy of present-day populations may not mirror optimal seed dormancy at the sites of origin, but rather reflect founder events or genetic correlations with traits more strongly related to fitness. This may seem less likely considering the strong effects of 
germination date for likelihood of seedling establishment, survival and fecundity in A. thaliana (e.g., Donohue et al., 2005; Akiyama \& Ågren, 2014; Postma \& Ågren, 2016; Zacchello et al., 2020). However, germination date is determined not only by dormancy at the time of seed maturation, but also by processes affected by the post-dispersal environment, such as rate at which dormancy is released, and possible acquirement of secondary dormancy (Montesinos et al., 2012; Postma et al., 2016; Martínez-Berdeja et al., 2020). To further explore the consequences of the documented variation in primary dormancy, it would be of interest to compare dormancy release under contrasting field conditions and examine whether any genotype $\times$ field environment interaction can be detected in this trait, since this should influence the realized germination time.

In conclusion, this study has documented strong differentiation in seed dormancy between Fennoscandian and Italian populations of $A$. thaliana, but also among populations within each of the two regions. The wide variation in seed dormancy documented among populations within the two geographic regions indicates considerable evolutionary flexibility, and is consistent with strong divergent selection on this trait. Within Fennoscandia, which was the best sampled region, we found an association between seed dormancy and temperature and precipitation, two climatic factors that are expected to change in the future (MassonDelmotte et al. 2018). Reciprocal seed and seedling transplants could be used to determine whether this among-population differentiation in seed dormancy contributes to local adaptation. Moreover, to assess the potential for adaptive evolution in response to ongoing changes in climate, future studies should examine the extent to which seed dormancy varies genetically within natural populations, and whether current gene flow among divergent populations is sufficient to maintain such variation.

\section{Data availability}

Data will be deposited in the Dryad digital repository after acceptance of the paper.

\section{Conflict of interest}

The authors have no conflict of interest to declare.

\section{Author contributions}

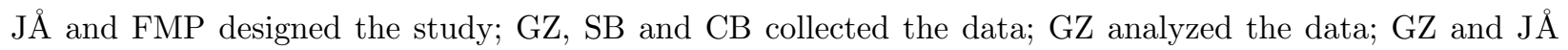
wrote the manuscript; all authors critically revised the manuscript, and gave final approval for publication.

\section{Acknowledgments}

This work was financially supported by a grant from the Swedish Research Council to JÅ. We thank Jenny Glans, Linus Vikström, Mattias Vass, Thomas Ellis and numerous assistants for their assistance in the field and in the greenhouse.

\section{References}

Ågren J, Schemske DW . 2012 . Reciprocal transplants demonstrate strong adaptive differentiation of the model organismArabidopsis thaliana in its native range. New Phytologist194 : 1112-1122.

Akiyama R, Ågren J . 2014 . Conflicting selection on the timing of germination in a natural population of Arabidopsis thaliana . Journal of Evolutionary Biology 27 : 193-199.

Alboresi A, Gestin C, Leydecker MT, Bedu M, Meyer C, Truong HN .2005 . Nitrate, a signal relieving seed dormancy in Arabidopsis.Plant, Cell and Environment 28 : 500-512.

Allen PS, Meyer SE . 1998 . Ecological aspects of seed dormancy loss. Seed Science Research 8 : 183-192.

Allen PS, Meyer SE . 2002 . Ecology and ecological genetics of seed dormancy in downy brome. Weed Science50 : 241-247.

Baskin CC, Baskin JM . 2014 . Seeds : ecology, biogeography, and evolution of dormancy and germination . San Diego, California: Academic Press. 
Bender MH, Baskin JM, Baskin CC . 2003 . Seed germination ecology of Polymnia canadensis (Asteraceae), a monocarpic species of the North American temperate deciduous forest. Plant Ecology 168 : 221-253.

Bewley JD, Bradford KJ (Kent J., Hilhorst HWM, Nonogaki H .2013 . Seeds : physiology of development, germination and dormancy. New York: Springer.

Buijs G, Vogelzang A, Nijveen H, Bentsink L . 2020 . Dormancy cycling: translation-related transcripts are the main difference between dormant and non-dormant seeds in the field.Plant Journal 102 : $327-339$.

Burghardt LT, Metcalf CJE, Wilczek AM, Schmitt J, Donohue K .2015 . Modeling the influence of genetic and environmental variation on the expression of plant life cycles across landscapes. The American Naturalist 185 : 212-227.

Chiang GCK, Bartsch M, Barua D, et al. 2011. DOG1 expression is predicted by the seed-maturation environment and contributes to geographical variation in germination inArabidopsis thaliana. Molecular Ecology 20 : 3336-3349.

Cochrane A, Yates CJ, Hoyle GL, Nicotra AB . 2015. Will among-population variation in seed traits improve the chance of species persistence under climate change? Global Ecology and Biogeography 24 : $12-24$.

Coughlan JM, Saha A, Donohue K . 2017 . Effects of pre- and post-dispersal temperature on primary and secondary dormancy dynamics in contrasting genotypes of Arabidopsis thaliana(Brassicaceae). Plant Species Biology 32 : 210-222.

Dawson TP, Jackson ST, House JI, Prentice IC, Mace GM .2011 . Beyond predictions: Biodiversity conservation in a changing climate. Science 332 : 53-58.

Debieu M, Tang C, Stich B, et al. 2013 . Co-Variation between seed dormancy, growth rate and flowering time changes with latitude in Arabidopsis thaliana. PLoS ONE8 : 1-12.

Donohue K . 2002 . Germination timing influences natural selection on life-history characters in Arabidopsis thaliana .Ecology 83 : 1006-1016.

Donohue K . 2009 . Completing the cycle: maternal effects as the missing link in plant life histories. Philosophical transactions of the Royal Society of London. Series B, Biological sciences 364 : 1059-74.

Donohue K, Dorn L, Griffith C, et al. 2005 . The evolutionary ecology of seed germination of Arabidopsis thaliana: Variable natural selection on germination timing. Evolution59 : 758-770.

Donohue K, Rubio de Casas R, Burghardt L, Kovach K, Willis CG .2010 . Germination, postgermination adaptation, and species ecological ranges. Annual Review of Ecology, Evolution, and Systematics 41 : 293-319.

Durvasula A, Fulgione A, Gutaker RM, et al.2017 . African genomes illuminate the early history and transition to selfing in Arabidopsis thaliana. Proceedings of the National Academy of Sciences of the United States of America114 : 5213-5218.

Evans AS, Cabin RJ . 1995 . Can dormancy affect the evolution of post-germination traits? The case of Lesquerella Fendleri. Ecology 76 : 344-356.

Fenner M . 2018. The effects of the parent environment on seed germinability. Seed Science Research 1 : 75-84.

Fenner MK, Thompson K . 2005 . The Ecology of Seeds . Cambridge: Cambridge University Press. 
Fernandez-Pascual E, Jimenez-Alfaro B, Caujape-Castells J, Jaen-Molina R, Diaz TE . 2013. A local dormancy cline is related to the seed maturation environment, population genetic composition and climate. Annals of Botany 112 : 937-945.

Fick SE, Hijmans RJ . 2017 . Worldclim 2: New 1-km spatial resolution climate surfaces for global land areas . https://worldclim.org/version2. 19 Nov. 2019.

Finch-Savage WE, Leubner-Metzger G . 2006 . Seed dormancy and the control of germination. New Phytologist171 : 501-523.

Footitt S, Douterelo-Soler I, Clay H, Finch-Savage WE .2011 . Dormancy cycling in Arabidopsis seeds is controlled by seasonally distinct hormone-signaling pathways. Proceedings of the National Academy of Sciences of the United States of America108 : 20236-41.

Footitt S, Huang Z, Clay HA, Mead A, Finch-Savage WE .2013 . Temperature, light and nitrate sensing coordinate Arabidopsis seed dormancy cycling, resulting in winter and summer annual phenotypes. The Plant Journal 74 : 1003-1015.

Hacker JB . 1984 . Genetic variation in seed dormancy inDigitaria milanjiana in relation to rainfall at the collection site. The Journal of Applied Ecology 21 : 947.

He H, De Souza Vidigal D, Basten Snoek L, et al.2014 . Interaction between parental environment and genotype affects plant and seed performance in Arabidopsis. Journal of Experimental Botany 65 : 6603-6615.

Kendall S, Penfield S . 2012 . Maternal and zygotic temperature signalling in the control of seed dormancy and germination.Seed Science Research $\mathbf{2 2}$.

Kerdaffrec E, Nordborg M . 2017 . The maternal environment interacts with genetic variation in regulating seed dormancy in Swedish Arabidopsis thaliana (P Yang, Ed.). PLOS ONE12 : e0190242.

Kronholm I, Pico FX, Alonso-Blanco C, Goudet J, Meaux J de .2012 . Genetic basis of adaptation in Arabidopsis thaliana : Local adaptation at the seed dormancy QTL DOG1.Evolution 66 : 2287-2302.

Li B, Foley ME . 1997. Genetic and molecular control of seed dormancy. Trends in Plant Science 2 : 384-389.

Llorens L, Pons M, Gil L, Boira H . 2008 . Seasonality of seed production and germination trends of Fumana ericoides (Cistaceae) in the west semiarid Mediterranean region. Journal of Arid Environments $\mathbf{7 2}$ : 121-126.

Martinez-Berdeja A, Stitzer MC, Taylor MA, et al.2020. Functional variants of DOG1 control seed chilling responses and variation in seasonal life-history strategies in Arabidopsis thaliana. Proceedings of the National Academy of Sciences of the United States of America 117 : 2526-2534.

Masson-Delmotte V, Zhai P, Portner H-O, et al.2018 . Global warming of 1.5degC . Geneva, Switzerland.

Meyer SE, Monsen SB . 1991. Habitat-correlated variation in mountain big sagebrush (Artemisia tridentata ssp. vaseyana) seed germination patterns. Ecology $72:$ 739-742.

Montesinos-Navarro A, Pico FX, Tonsor SJ . 2012 . Clinal variation in seed traits influencing life cycle timing inArabidopsis thaliana. Evolution 66 : 3417-3431.

Postma FM, Agren J . 2015 . Maternal environment affects the genetic basis of seed dormancy in Arabidopsis thaliana .Molecular Ecology 24 : 785-797.

Postma FM, Agren J . 2016 . Early life stages contribute strongly to local adaptation in Arabidopsis thaliana .Proceedings of the National Academy of Sciences 113 : 7590-7595. 
Postma FM, Lundemo S, Agren J . 2016 . Seed dormancy cycling and mortality differ between two locally adapted populations of Arabidopsis thaliana. Annals of Botany 117 : 249-256.

Schutz W, Milberg P . 1997 . Seed Dormancy inCarex canescens : Regional Differences and Ecological Consequences. Oikos $78: 420$.

Schutz W, Rave G . 2003 . Variation in seed dormancy of the wetland sedge, Carex elongata, between populations and individuals in two consecutive years. Seed Science Research13 : 315-322.

Vidigal DS, Marques ACSS, Willems L a J, et al.2016 . Altitudinal and climatic associations of seed dormancy and flowering traits evidence adaptation of annual life cycle timing inArabidopsis thaliana . Plant, cell \& environment : 1-12.

Vleeshouwers LM, Bouwmeester HJ, Karssen CM . 1995 . Redefining Seed Dormancy: An Attempt to Integrate Physiology and Ecology. The Journal of Ecology 83 : 1031.

Wadgymar SM, Cumming MN, Weis AE . 2015. The success of assisted colonization and assisted gene flow depends on phenology. Global Change Biology 21 : 3786-3799.

Wadgymar SM, Lowry DB, Gould BA, Byron CN, Mactavish RM, Anderson JT . 2017 . Identifying targets and agents of selection: Innovative methods to evaluate the processes that contribute to local adaptation. Methods in Ecology and Evolution 8 : 738-749.

Wagmann K, Hautekeete N-C, Piquot Y, Meunier C, Schmitt SE, Van Dijk H . 2012 . Seed dormancy distribution: Explanatory ecological factors. Annals of Botany 110 : 1205-1219.

Wilczek AM, Roe JL, Knapp MC, et al. 2009 . Effects of genetic perturbation on seasonal life history plasticity.Science (New York, N.Y.) $323: 930-4$.

Young JA, Palmquist DE, Evans RA . 1991. Temperature profiles for germination of big sagebrush seeds from native stands. Journal of Range Management 44 : 385-390.

Zacchello G, Vinyeta M, Agren J . 2020 . Strong stabilizing selection on timing of germination in a Mediterranean population of Arabidopsis thaliana . American Journal of Botany 107 : 1518-1526.

Table 1. The effects of region of origin (Italy or Fennoscandia), maternal environment (greenhouse or Italy field site) and their interaction (fixed effects) and population nested within region of origin and its interaction with maternal environment (random effects, in italics) on germination proportion 12 weeks after seed maturation examined with mixed-effect ANOVA. The analysis was based on line means. Statistical significance of fixed explanatory variables was determined by F-tests, and significance of random factors was tested using Likelihood Ratio Tests between full and reduced models. Statistically significant effects $(\mathrm{P}<0.05)$ are in bold.

\begin{tabular}{llll}
\hline Source of variation & $\delta \varphi / \Delta \delta \varphi$ & Germination proportion & Germination proportion \\
\hline & & F or L-ratio & $\mathbf{P}$ \\
Region & $41 / 1$ & 69.7 & $<\mathbf{0 . 0 0 1}$ \\
Maternal environment & $331 / 1$ & 15.4 & $<\mathbf{0 . 0 0 1}$ \\
Region $\times$ Maternal env & $331 / 1$ & 1.2 & 0.27 \\
Population (Region) & $7 / 6$ & 107.5 & $<\mathbf{0 . 0 0 1}$ \\
Population $\times$ Maternal env & $9 / 7$ & 158.8 & $<\mathbf{0 . 0 0 1}$ \\
\hline
\end{tabular}

Table 2. The effects of population, maternal environment (Italian or Swedish field site) and their interaction on germination proportion 12 weeks after seed maturation of Fennoscandian populations examined with ANOVA. The analysis was based on line means. Statistical significance of effect variables was determined by F-tests. Statistically significant effects $(\mathrm{P}<0.05)$ are in bold. 


\begin{tabular}{llll}
\hline Source of variation & $\delta \varphi / \Delta \delta \varphi$ & $\mathbf{F}$ & $\mathbf{P}$ \\
\hline Population & $113 / 17$ & 11.3 & $<\mathbf{0 . 0 0 1}$ \\
Maternal environment & $113 / 1$ & 0.2 & 0.63 \\
Population $\times$ Maternal env & $113 / 17$ & 5.4 & $<\mathbf{0 . 0 0 1}$ \\
\hline
\end{tabular}

Table 3. Factor loadings of climatic variables on principle components. In bold are loading factors with absolute values greater than 0.40 .

\begin{tabular}{lllll}
\hline Region & Variable & PC1 & PC2 & PC3 \\
\hline Fennoscandia & Annual temperature & -0.289 & $\mathbf{- 0 . 7 1 7}$ & $\mathbf{- 0 . 5 3 7}$ \\
& Maximum temperature of the warmest month & $\mathbf{- 0 . 5 1 3}$ & -0.043 & $\mathbf{0 . 5 7 3}$ \\
& Mean temperature of the warmest quarter & $\mathbf{- 0 . 4 9 1}$ & -0.324 & 0.325 \\
& Annual precipitation & $\mathbf{0 . 4 4 1}$ & $\mathbf{- 0 . 4 9 2}$ & 0.138 \\
& Mean precipitation of the warmest quarter & $\mathbf{0 . 4 6 6}$ & -0.369 & $\mathbf{0 . 5 0 9}$ \\
Italy & $\mathbf{0 . 5 2 3}$ & 0.279 & 0.345 \\
& Annual temperature & $\mathbf{0 . 5 3 1}$ & 0.133 & $\mathbf{- 0 . 4 6 3}$ \\
& Maximum temperature of the warmest month & 0.218 & 0.090 \\
Mean temperature of the warmest quarter & -0.267 & $\mathbf{0 . 6 6 4}$ & $\mathbf{0 . 5 2 2}$ \\
& Annual precipitation & -0.249 & $\mathbf{0 . 6 4 5}$ & $\mathbf{- 0 . 6 2 1}$ \\
\hline
\end{tabular}

Table 4. The association between the first three principal components extracted from principal component analysis of climatic variables and mean germination proportions of populations of Arabidopsis thaliana sampled in Fennoscandia and Italy examined with multiple regression. Germination proportion was recorded among seeds that had been stored dry for 1, 2 and 12 weeks after seed maturation in the greenhouse, and for 12 weeks after seed collection at an Italian and a Swedish field site. Statistically significant effects $(\mathrm{P}<0.05)$ are in bold.

\begin{tabular}{|c|c|c|c|}
\hline Maternal environment/time after ripening & Source of variation & Partial regression coefficient $( \pm \mathrm{SE})$ & $\mathbf{P}$ \\
\hline \multicolumn{4}{|l|}{ Fennoscandian populations } \\
\hline \multirow[t]{3}{*}{ Greenhouse/1 week } & $\mathrm{PC} 1$ & $0.0387 \pm 0.0171$ & \\
\hline & $\mathrm{PC} 2$ & $-0.0171 \pm 0.0287$ & \\
\hline & PC3 & $0.0427 \pm 0.0663$ & \\
\hline \multirow[t]{3}{*}{ Greenhouse/3 weeks } & $\mathrm{PC} 1$ & $0.0799 \pm 0.0241$ & \\
\hline & $\mathrm{PC} 2$ & $-0.0172 \pm 0.0403$ & \\
\hline & PC3 & $0.0415 \pm 0.0934$ & \\
\hline \multirow[t]{3}{*}{ Greenhouse/12 weeks } & $\mathrm{PC} 1$ & $0.0600 \pm 0.0364$ & \\
\hline & $\mathrm{PC} 2$ & $0.0108 \pm 0.0611$ & \\
\hline & PC3 & $0.0991 \pm 0.1414$ & 0 \\
\hline \multirow[t]{3}{*}{ Sweden/12 weeks } & $\mathrm{PC} 1$ & $0.0263 \pm 0.0239$ & 0 \\
\hline & $\mathrm{PC} 2$ & $-0.00002 \pm 0.0400$ & \\
\hline & PC3 & $0.1011 \pm 0.0926$ & 0.2 \\
\hline \multirow[t]{3}{*}{ Italy/12 weeks } & PC1 & $-0.0132 \pm 0.0095$ & 0.1 \\
\hline & $\mathrm{PC} 2$ & $0.0244 \pm 0.0152$ & 0 \\
\hline & PC3 & $-0.0179 \pm 0.0375$ & 0 \\
\hline \multicolumn{4}{|l|}{ Italian populations } \\
\hline \multirow[t]{3}{*}{ Greenhouse/1 week } & PC1 & $0.0011 \pm 0.0012$ & 0 \\
\hline & $\mathrm{PC} 2$ & $-0.0004 \pm 0.0016$ & \\
\hline & PC3 & $-0.0040 \pm 0.0025$ & \\
\hline
\end{tabular}




\begin{tabular}{llll}
\hline Maternal environment/time after ripening & Source of variation & Partial regression coefficient $( \pm \mathbf{S E})$ & $\mathbf{P}$ \\
\hline Greenhouse/3 weeks & PC1 & $0.0012 \pm 0.0043$ & 0.79 \\
& PC2 & $0.0058 \pm 0.0060$ & 0.3 \\
Greenhouse/12 weeks & PC3 & $0.0028 \pm 0.0094$ & 0.7 \\
& PC1 & $-0.0393 \pm 0.0365$ & 0.30 \\
Italy/12 weeks & PC3 & $-0.0044 \pm 0.0512$ & 0.9 \\
& PC1 & $-0.0670 \pm 0.0797$ & 0.4 \\
& PC2 & $-0.0175 \pm 0.0446$ & 0.70 \\
& PC3 & $0.0389 \pm 0.0626$ & 0.5 \\
\end{tabular}

Figure 1. Map indicating locations of the study populations in Fennoscandia (blue symbols) and Italy (red symbols), and of the two common gardens (triangles), one in Sweden (Rödåsen) and one in Italy (Castelnuovo di Porto).

Figure 2. Climate at the site of origin of the natural populations of Arabidopsis thaliana sampled in Italy (in red) and Fennoscandia (in blue). (A) Mean monthly temperature (@C), and (B) Mean monthly precipitation $(\mathrm{mm})$. Data retrieved from the WorldClim database (Fick and Hijmans 2017).

Figure 3. Mean germination proportion (number of seeds germinating per viable seed sown) of natural populations of Arabidopsis thaliana sampled in Italy (in red) and Fennoscandia (in blue) (A) 12 weeks after seed harvest in three maternal environments: greenhouse, the Italian field site (Castelnuovo di Porto), and the Swedish field site (Rödåsen), and (B) 1, 3, 12, 30 and 54 weeks after seed maturation in the greenhouse. Regional means are indicated in bold. 

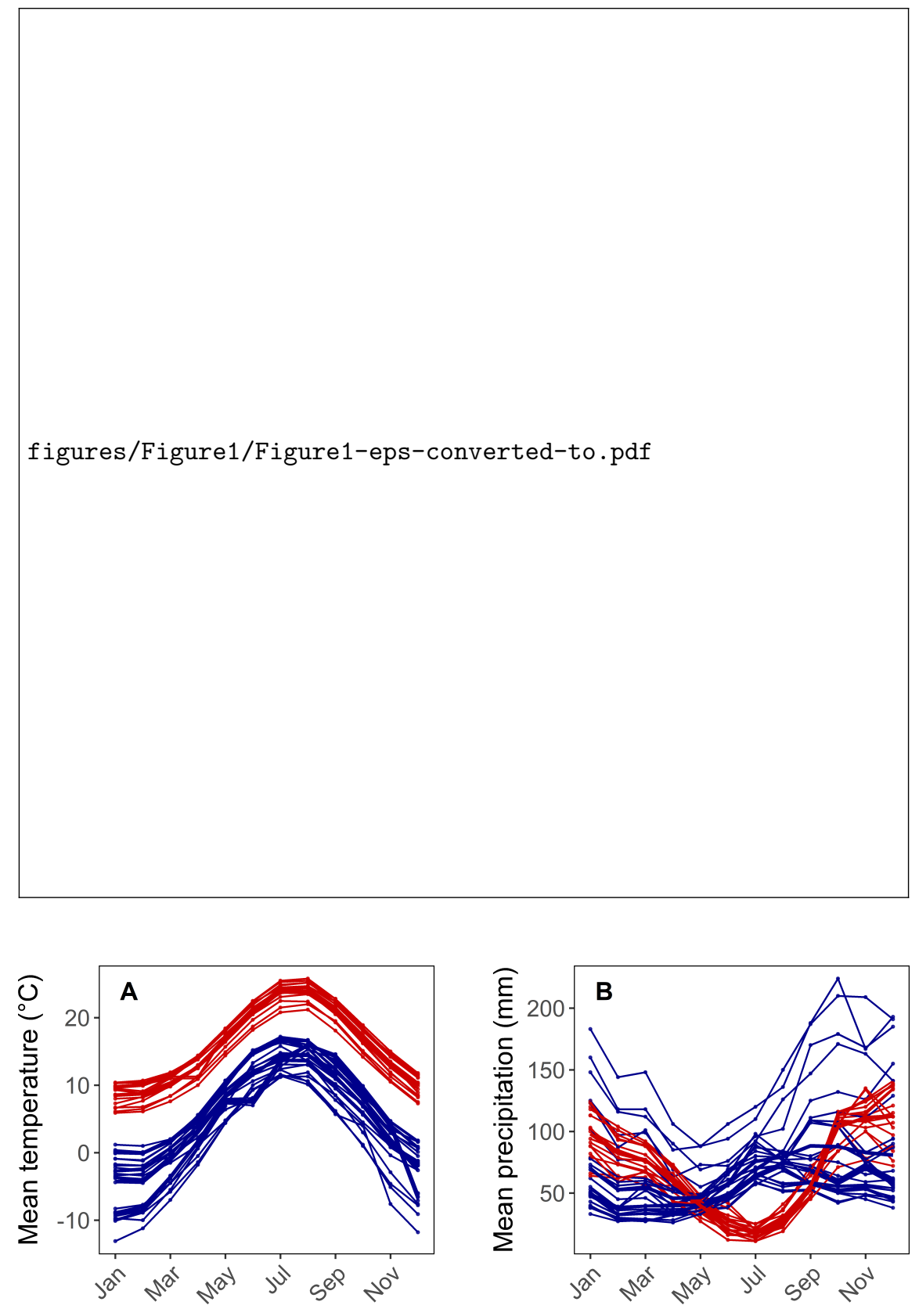

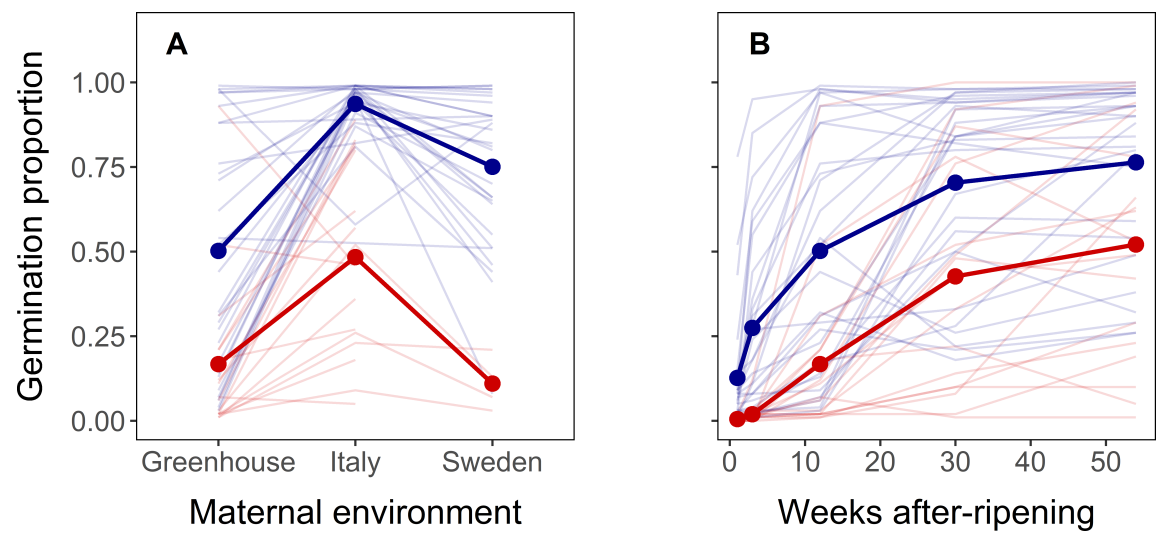